\title{
Protective and therapeutic effects of Trianthema portulacastrum against atherosclerosis in male albino rats via G-protein-coupled receptor 124
}

\author{
Haoyu Wu ${ }^{1,2}$, Tianjiao Gao ${ }^{3}$, Yiwei Cao ${ }^{4}$, Jiayu Diao² ${ }^{2}$ Fengjun Chang ${ }^{2}$, Jie Qi and Congxia Wang ${ }^{\text {* }}$
}

\begin{abstract}
Atherosclerosis is a severe cardiovascular disease characterized by narrowing of the lumen, plaque formation, and blood flow turbulence as a result of cholesterol and lipid accumulation in the inner lining of arteries. Bishkhapra (Trianthema portulacastrum Linn.) is a well-known common weed belonging to the family Aizoaceae. Several bioactive compounds have been isolated from this weed and widely used against several diseases. The present study evaluated the protective and therapeutic efficacies of T. portulacastrum against atherosclerosis in a rat model. The animals were divided into the sham, control (diabetes- + atherosclerosis-inducing diet), $100 \mathrm{mg} / \mathrm{kg}$ T. portulacastrum treatment, $200 \mathrm{mg} / \mathrm{kg}$ T. portulacastrum treatment, and positive control groups. Blood glucose, cholesterol, triglyceride, and other lipid parameters, as well as the expression of G-protein-coupled receptor 124 (GPR124), were measured. Glucose, cholesterol, and triglycerides were significantly reduced to near normal levels. The serum levels of fibrinogen, sVCAM1, and oxidized low density lipoproteins were substantially increased in control rats. Treatment with the T. portulacastrum extract reversed these levels to near normal levels. The mRNA expression of GPR124 was increased by 150\% in the control group. However, treatment with T. portulacastrum extract decreased the mRNA expression up to 40\% compared with the control group. Rats treated with 100 and $200 \mathrm{mg} / \mathrm{kg}$ T. portulacastrum extract showed a decrease in GPR124 protein expression by $9.5 \%$ and 33.3\%, respectively. Taken together, the results suggest that an extract of $T$. portulacastrum is effective against atherosclerosis in streptozotocin-induced diabetic rats.
\end{abstract}

Keywords: Diabetic rats, Atherosclerosis, Glucose, Cholesterol, Triglycerides

\section{Introduction}

Atherosclerosis is a severe cardiovascular disease (Bader 2010) characterized by narrowing of the lumen, plaque formation, and blood flow turbulence resulting from cholesterol and lipid accumulation in the inner lining of arteries (Ye et al. 2013). Risk factors of atherosclerosis are abnormal lipid metabolism, dysfunction of arterial lining and inflammatory reactions (Jaipersad et al. 2014). An association between atherosclerosis risk and plasma lipid levels has been reported (Matsumoto et al.

\footnotetext{
*Correspondence: CandiceStoutlzj@yahoo.com

${ }^{1}$ Department of Cardiology, The Second Affiliated Hospital, Xi'an Jiaotong University, Xi'an 710004, Shaanxi, China

Full list of author information is available at the end of the article
}

2014). Zhang et al. (2013) reported that atherosclerotic plaque formation is caused by an inflammatory response to injury. Endothelial lining dysfunction in lesion-prone areas of the arterial vasculature may be an early indicator of atherosclerosis (Gimbrone and Garcia-Cardena 2016). It has also been reported that an increased blood level of low density lipoprotein (LDL) is the primary cause of atherosclerosis (Ference et al. 2017), and that the development of atherosclerosis, despite a low LDL level, is associated with several risk factors, including diabetes mellitus, smoking, genetic factors, and male sex (Aikawa et al. 2001). G-protein-coupled receptor 124 (GPR124) is an orphan receptor of the GPCR subfamily. Gong et al. (2018) reported that GPR124 increases the pathogenesis of atherosclerosis via activation of inflammation. 
Plant-derived medicines have been used extensively for the treatment of several severe diseases (Sofowora et al. 2013). The World Health Organization reports that more than $80 \%$ of the population depends on plant-derived medicines for treatment (Ye et al. 2013). Bishkhapra (Trianthema portulacastrum Linn.) is a common weed belonging to the family Aizoaceae. Several bioactive compounds have been isolated from this weed and widely used against several diseases (Kumar et al. 2007). Protective effects of $T$. portulacastrum have been reported in rats fed an atherosclerosis-inducing diet (Shyam Sunder et al. 2010) and in rats induced to develop nephrotic syndrome (Karim 2012). Thus, the present study evaluated the protective and therapeutic efficacies of $T$. portulacastrum against atherosclerosis in rats.

\section{Materials and methods}

Rats

Male albino rats (180-210 g) were purchased from the animal house of Xi'an Jiaotong University, Xi'an, Shaanxi, and China. Animals were kept in standard rat polypropylene cages $(435 \times 290 \times 150 \mathrm{~mm}$; six rats per cage $)$ and maintained under standard conditions of $12 \mathrm{~h}$ light/12 h dark at a relative humidity of $60 \pm 5 \%$ and temperature of $25 \pm 0.5^{\circ} \mathrm{C}$ with food and water provided ad libitum.

\section{Preparation of plant materials}

Trianthema portulacastrum plants were collected from a local region in Shanghai, China (Voucher specimen: 2018-341). Leaves were washed repeatedly in tap water, dried in sunlight, and ground into a fine powder. The prepared powder was packed into a Soxhlet apparatus and extracted with methanol (70\%) in water for $22 \mathrm{~h}$ at $70{ }^{\circ} \mathrm{C}$. The methanol extract was evaporated at $45^{\circ} \mathrm{C}$ and then dried in a vacuum oven and stored for further use (Anil et al. 2018).

\section{Experimental diabetes}

Experimental diabetes was induced by single intraperitoneal administration of streptozotocin $(\mathrm{pH} 4.5 ; 45 \mathrm{mg} /$ $\mathrm{kg}$ in citrate buffer) to fasted rats (12 h). Streptozotocinadministered rats exhibited a hyperglycemia (glucose level: $250 \mathrm{mg} / \mathrm{dL}$ ) within $48 \mathrm{~h}$ (Graham et al. 2011).

\section{Induction of atherosclerosis}

Experimental atherosclerosis was induced by feeding rats an atherosclerosis-inducing diet. The diet contained $1.5 \mathrm{~mL}$ olive oil, $40 \mathrm{mg}$ cholesterol, and $8 \mathrm{mg}$ vitamin D2. The diet was given to rats daily for 5 days (Sharma et al. 2010).

\section{Experimental groups}

The rats were divided into the following groups: sham, control (diabetes- + atherosclerosis-inducing diet), $100 \mathrm{mg} / \mathrm{kg} \mathrm{T}$. portulacastrum treatment, $200 \mathrm{mg} / \mathrm{kg} \mathrm{T}$. portulacastrum treatment, and positive control $(600 \mu \mathrm{g} /$ $\mathrm{kg}$ glibenclamide). Sham and control rats were given normal saline, whereas treated rats received the $T$. portulacastrum extract or glibenclamide $(1 \mathrm{~mL})$. The treatment was continued daily for 45 consecutive days.

\section{Biomarkers}

The levels of blood glucose, total cholesterol, triglycerides, high density lipoprotein-cholesterol (HDL-C), LDL-cholesterol (LDL-C), and very low density lipoprotein-cholesterol were measured according to previously described methods (Wang et al. 2010; Aberare et al. 2011). Plasma fibrinogen and sVCAM-1 levels were measured using an enzyme-linked immunosorbent assay kit. Oxidized LDL and nitric oxide (NO) end products were determined according to a previously described method (Bryan and Grisham 2007; Itabe 2012). Apolipoprotein (Apo)-A and Apo-B levels were measured according to a previously described method (Cho et al. 2012)

\section{RT-PCR}

Total RNA was isolated from heart tissue, and the RNA integrity was determined by gel electrophoresis. The RNA purity was determined by absorbance measurements at $260 \mathrm{~nm}$. To produce cDNA, an oligo dT primer $(0.5 \mathrm{ng}), 10 \mathrm{mM}$ dNTPs $(2 \mu \mathrm{L})$, reverse transcriptase (100 $\mathrm{U})$, and $5 \times \mathrm{RT}$ buffer $(4 \mu \mathrm{L})$ were added to the total RNA $(1 \mu \mathrm{g})$ in PCR tubes. The PCR tubes were incubated in a thermal cycler for $1 \mathrm{~h}$ at room temperature and then for $10 \mathrm{~min}$ at $90{ }^{\circ} \mathrm{C}$. The relative mRNA expression of GPR124 was determined by RT-PCR (Table 1) according to Masatoshi et al. (2001).

Table 1 List of RT-PCR primers used in this study

\begin{tabular}{llll}
\hline S. No & Gene name & Forward primer & Reverse primer \\
\hline 1 & GPR124 & 5'-AGCAAGAGGGGATTTCACAAT-3' $^{\prime 2}$ & 5'-GGTCGTTCTACTGGGCTGATT-3' $^{\prime}$ \\
\hline GAPDH & 5'-GGTCACCAGGGCTGCTTTT-3' $^{\prime}$ & $5^{\prime}$-ATCTCGCTCCTGGAAGATGGT-3' \\
\hline
\end{tabular}




\section{Immunohistochemistry}

Heart tissues were dissected and sectioned. The tissue sections were then fixed in formalin, embedded in paraffin, deparaffinized, and rehydrated with xylene using a graded alcohol series. A 3\% hydrogen peroxide solution was added to inhibit endogenous peroxidase activity, followed by $2 \%$ bovine serum albumin to block nonspecific binding sites. Heart tissues were incubated with an antiGPR124 antibody (1:300 dilutions, ab198817; Abcam, Cambridge, UK) overnight and then with a horseradish peroxidase-conjugated goat anti-rat antibody (1:300 dilutions, ab6721, Abcam) for 60 min (Balic et al. 2011). Immunofluorescence was visualized using a confocal microscope to assess GPR124 expression.

\section{Statistical analysis}

Experimental results are expressed as the mean \pm standard deviation. The results were compared by one-way analysis of variance, followed by Tukey's post hoc test. The differences between the control and treated samples were considered significant at $P<0.05$.

\section{Results}

In this study, we evaluated the protective and therapeutic efficacies of T. portulacastrum against atherosclerosis in a rat model. The blood glucose level was significantly reduced by $20.6 \%$ and $58.3 \%$ in control rats supplemented with 100 and $200 \mathrm{mg} / \mathrm{kg} \mathrm{T}$. portulacastrum extract, respectively (Fig. $1, P<0.05$ ), and by $65 \%$ in rats treated with glibenclamide, compared with untreated rats (Fig. 1; $P<0.05)$. The total cholesterol level was increased by $131.7 \%$ in the diabetic rats but was significantly reduced by $24.6 \%$ and $42.2 \%$ in the control rats supplemented with 100 and $200 \mathrm{mg} / \mathrm{kg} \mathrm{T}$. portulacastrum extract, respectively (Fig. 2; $P<0.05$ ), and by $49 \%$ in rats treated with glibenclamide, compared with the untreated controls (Fig. $2, P<0.05$ ). The triglyceride level was increased by $96.2 \%$ in diabetic rats but was significantly reduced by $7.5 \%$ and $19.4 \%$ in control rats supplemented with 100 and $200 \mathrm{mg} / \mathrm{kg} \mathrm{T}$. portulacastrum extract, respectively (Fig. 3; $P<0.05$ ), and by $29.2 \%$ in rats treated with glibenclamide, compared with the untreated animals (Fig. 3, $P<0.05)$.

The serum lipid profiles of the sham, control, extract, and glibenclamide groups are listed in Table 2. Diabetic rats showed increased LDL-C and decreased HDL-C levels compared with the sham rats (Table 2; $P<0.05$ ). However, treatment with the T. portulacastrum extract significantly prevented these effects, with nearly normal LDL-C and HDL-C levels observed in treated rats (Table 2; $P<0.05$ ). Serum levels of fibrinogen, sVCAM1 , and oxidized LDL were significantly increased in

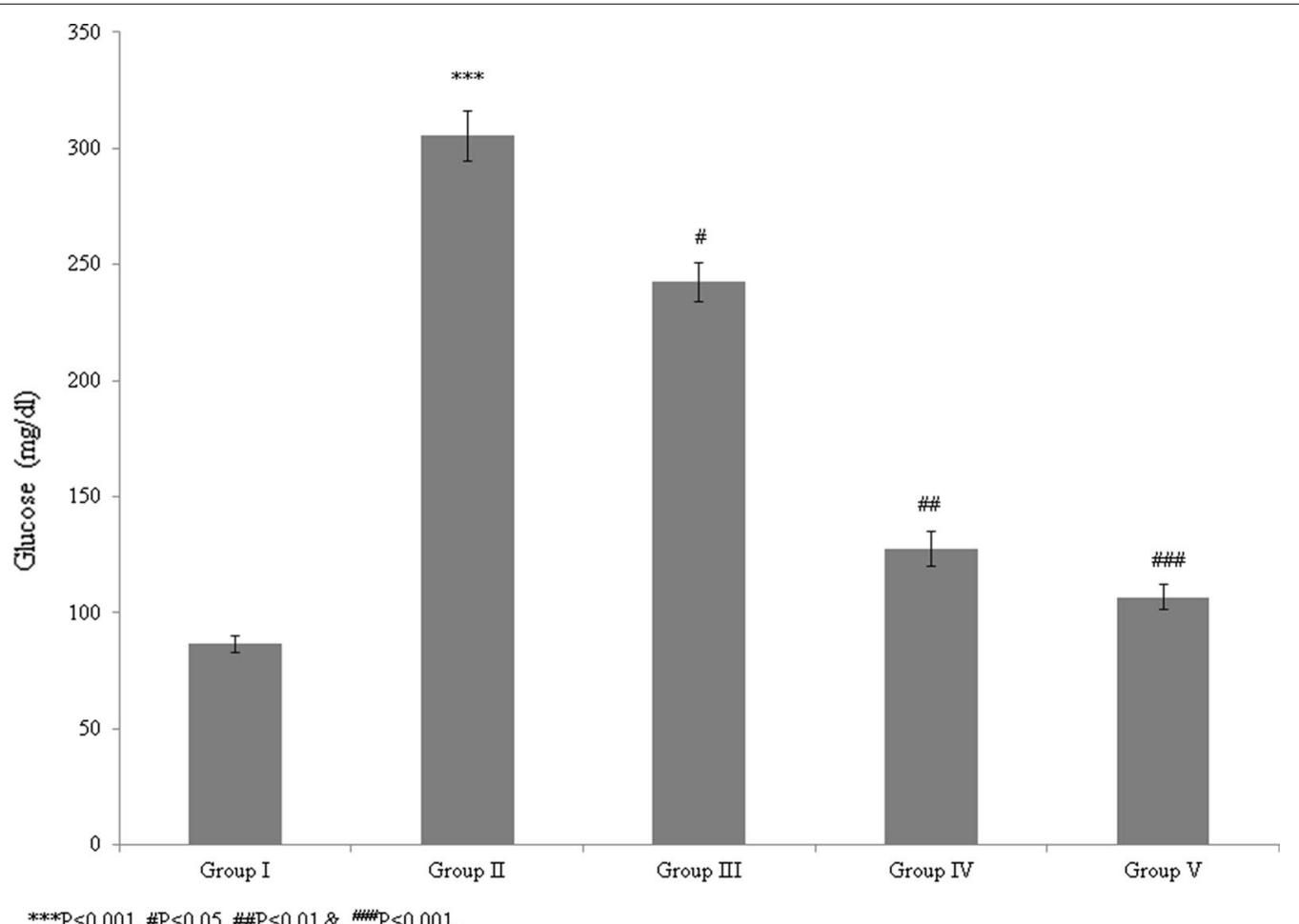

Fig. 1 Protective effect of a T. portulacastrum extract on serum blood glucose levels (mg/dL) in normal diabetic rats. ${ }^{* *} P<0.001 \mathrm{vs}$. sham; ${ }^{\#} P<0.05$, ${ }^{\# \#} P<0.01$, and ${ }^{\# \#} P<0.001$ vs. control. $N=6$ 


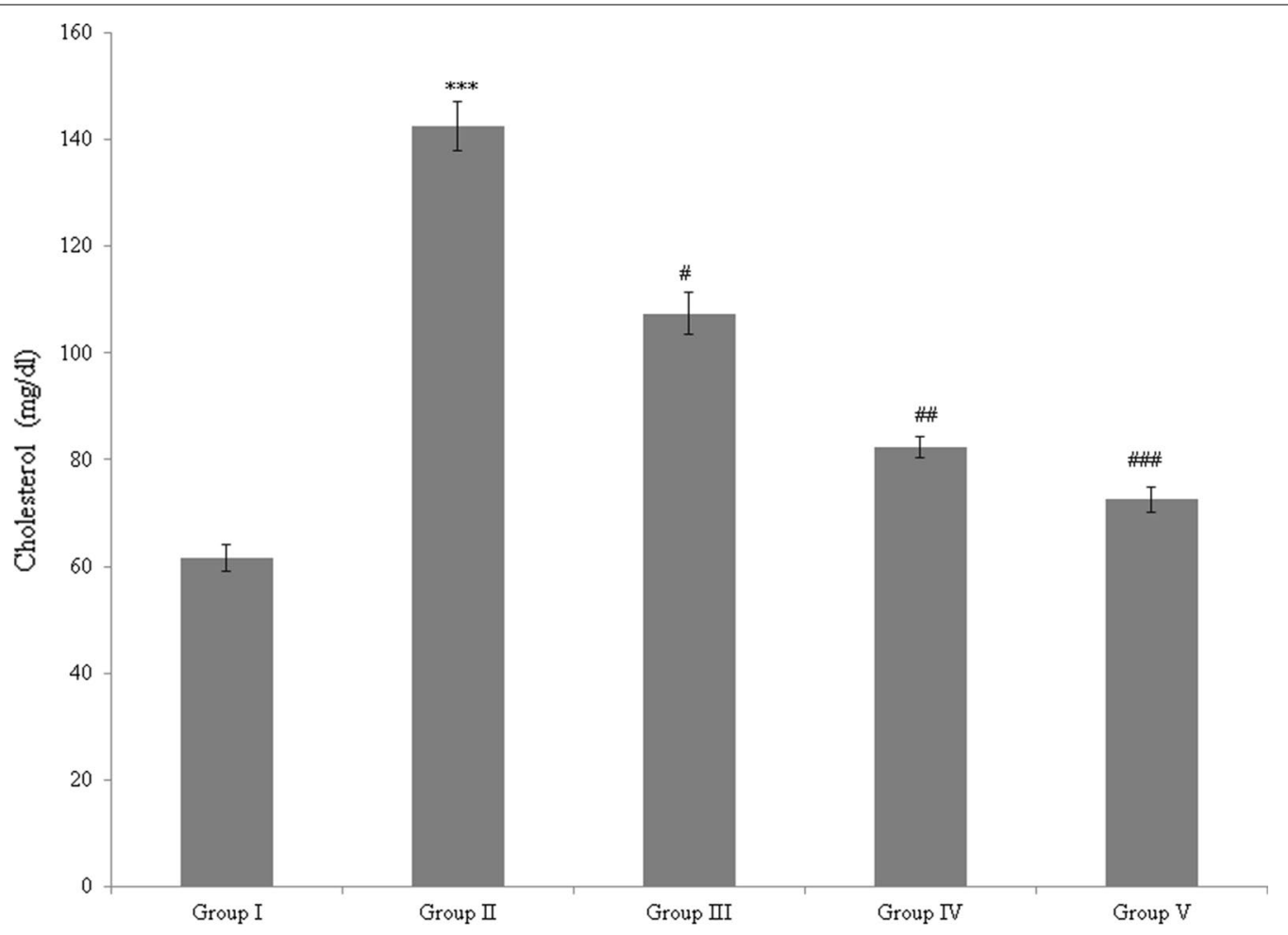

$* * * \mathrm{P}<0.001, \# \mathrm{P}<0.05, \# \mathrm{P}<0.01 \& * 4 \mathrm{P}<0.001$,

Fig. 2 The protective effect of a T. portulacastrum extract on blood cholesterol levels $(\mathrm{mg} / \mathrm{dL})$ in normal diabetic rats. ${ }^{* * *} P<0.001 \mathrm{vs}$. sham; ${ }^{\#} P<0.05$; ${ }^{\#} P<0.01 ; \# \#<0.001$ vs. control. $N=6$

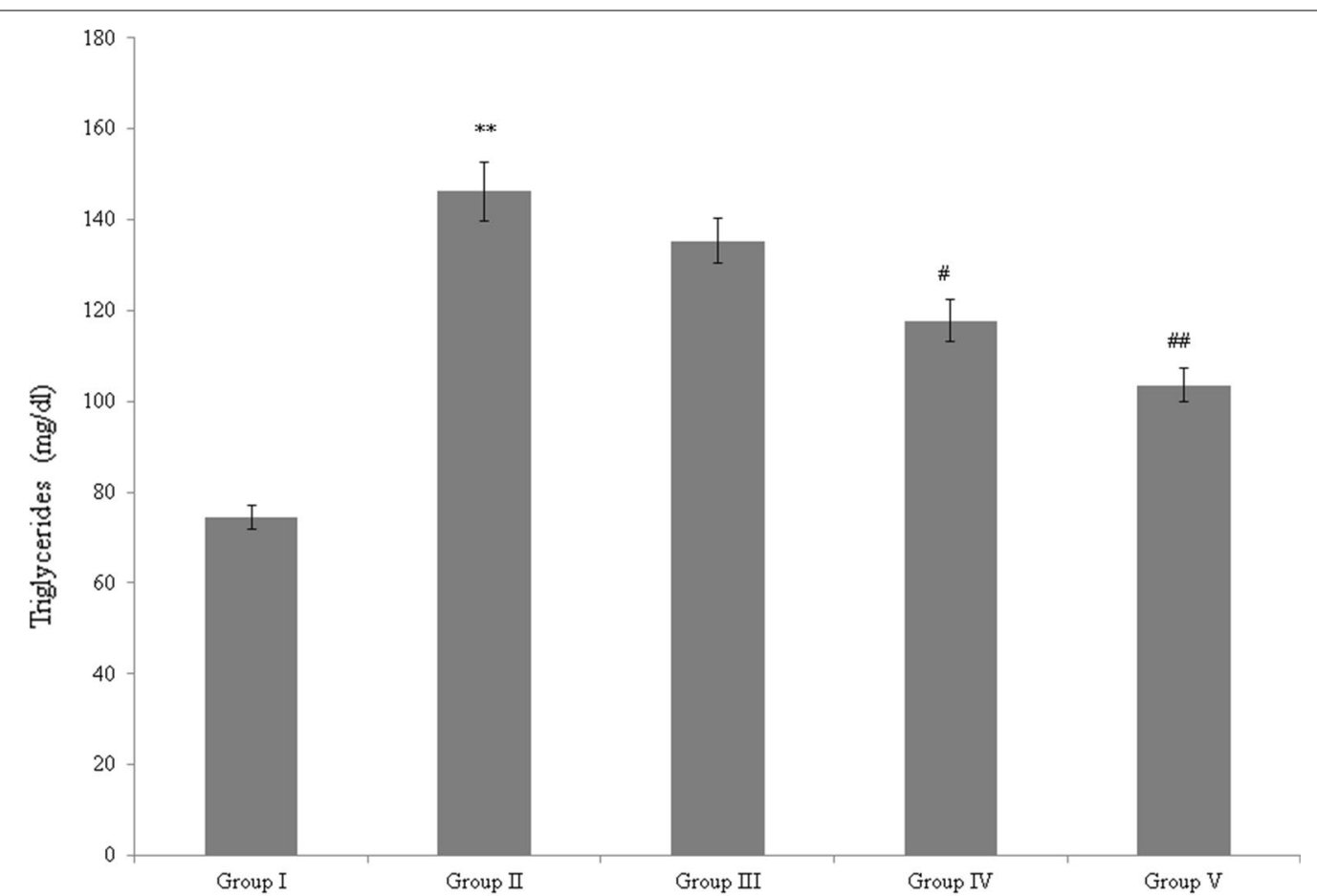

$* * \mathrm{P}<0.01, \# \mathrm{P}<0.05 \& \# \mathrm{P}<0.01$

Fig. 3 The protective effect of a T. portulacastrum extract on triglyceride levels (mg/dL) in normal diabetic rats. ${ }^{* *} P<0.01$ vs. sham; ${ }^{\#} P<0.05$ and ${ }^{\#} P<0.01$ vs. control. $N=6$ 
Table 2 Protective effect of $T$. portulacastrum extract on lipid profile in streptozotocin induced diabetic rats

\begin{tabular}{llllll}
\hline Parameter & Group I & Group II & $\begin{array}{l}\text { Group } \\
\text { III }\end{array}$ & Group IV Group V \\
\hline HDL-C & $34.8 \pm 2.1$ & $18.6 \pm 1.2^{* *}$ & $20.7 \pm 1.4$ & $28.4 \pm 2.1^{\#}$ & $30.2 \pm 1.9^{\# \#}$ \\
LDL-C & $15.6 \pm 1.1$ & $67.4 \pm 3.7^{* * *}$ & $58.1 \pm 3.5$ & $44.5 \pm 2.4^{\#}$ & $30.3 \pm 1.4^{\# \# \#}$ \\
VLDL-C & $14.3 \pm 0.7$ & $28.5 \pm 1.3^{* *}$ & $25.3 \pm 1.4$ & $20.3 \pm 1.2^{\#}$ & $18.4 \pm 1.1^{\# \#}$ \\
\hline${ }^{* *} P<0.01,{ }^{* * *} P<0.001,{ }^{\#} P<0.05,{ }^{\# \#} P<0.01$ and $^{\# \# \#} P<0.001$
\end{tabular}

Table 3 Protective effect of $T$. portulacastrum extract on endothelial dysfunction streptozotocin induced diabetic rats

\begin{tabular}{llllll}
\hline Parameter & Group I & Group II & Group III & Group IV & Group V \\
\hline Apo-A & - & $41 \downarrow$ & $8.2 \uparrow$ & $18.3 \uparrow$ & $23.2 \uparrow$ \\
Apo-B & - & $23.5 \uparrow$ & $7.3 \downarrow$ & $16.3 \downarrow$ & $18.3 \downarrow$ \\
NO levels $(\mu \mathrm{mol} / \mathrm{L})$ & - & $28.3 \downarrow$ & $13.3 \uparrow$ & $18.2 \uparrow$ & $26.5 \uparrow$ \\
Ox-LDL $(\mu \mathrm{mol} / \mathrm{L})$ & - & $37.3 \uparrow$ & $8.4 \downarrow$ & $19.2 \downarrow$ & $24.3 \downarrow$ \\
\hline
\end{tabular}

$\uparrow: \%$ increase, $\downarrow$ : \% decrease

diabetic rats compared with the sham rats (Tables 3 and $4 ; P<0.05)$ but were near normal levels in the rats treated with the $T$. portulacastrum extract (Tables 3 and 4; $P<0.05)$.

The NO level was significantly reduced in diabetic rats, but treatment with the $T$. portulacastrum extract in these rats significantly increased the NO level to nearly normal levels (Table $3 ; P<0.05$ ). Furthermore, treatment of diabetic rats with the $T$. portulacastrum extract significantly improved the Apo-A and Apo-B levels (Table 4; $P<0.05)$. The mRNA expression of GPR124 was significantly increased by $150 \%$ in diabetic rats compared with the sham rats (Fig. $4 ; P<0.05$ ). However, the rats treated with 100 and $200 \mathrm{mg} / \mathrm{kg}$ T. portulacastrum extract exhibited significantly reduced GPR124 mRNA expression, by $8 \%$ and $40 \%$, respectively (Fig. $4 ; P<0.05$ ). The protein expression of GPR124 was substantially increased by $130 \%$ in diabetic rats compared with sham rats (Fig. 5; $P<0.05)$. However, the diabetic rats treated with 100 and $200 \mathrm{mg} / \mathrm{kg} \mathrm{T}$. portulacastrum extract exhibited significantly reduced GPR 124 protein expression, by $9.5 \%$ and $33.3 \%$, respectively (Fig. $5 ; P<0.05$ ).

\section{Discussion}

In this study, we evaluated the protective and therapeutic effects of $T$. portulacastrum against atherosclerosis in a rat model. Atherosclerosis is a severe cardiovascular disease (Bader 2010) characterized by narrowing of the lumen, plaque formation, and blood flow turbulence resulting from cholesterol and lipid accumulation in the inner lining of arteries (Ye et al. 2013). Arterial lining dysfunction, abnormal lipid metabolism, and inflammatory reactions are the main risk factors for atherosclerosis (Jaipersad et al. 2014). Investigators have reported the association of the risk of atherosclerosis with levels of plasma lipids (Matsumoto et al. 2014). Zhang et al. (2013) have reported that atherosclerotic plaque formation is due to an inflammatory response to injury. Investigators have reported that dysfunctions of the endothelial lining of lesion-prone parts of the arterial vasculature were considered as early indicators of atherosclerosis (Gimbrone and Garcia-Cardena 2016).

An increase in the blood level of LDL is reported to be the primary cause of atherosclerosis (Ference et al. 2017), and the development of atherosclerosis, despite a low level of LDL, is associated with several risk factors, including diabetes mellitus, smoking, genetic factors, and male sex (Aikawa et al. 2001). Several bioactive compounds have been isolated from the $T$. portulacastrum weed and widely used against several diseases (Kumar et al. 2007). Investigators have reported the protective effect of $T$. portulacastrum in rats fed an atherosclerosisinducing diet (Shyam Sunder et al. 2010). Anreddy et al. (2010) reported the hypolipidemic and hypoglycemic activities of $T$. portulacastrum in alloxan-induced diabetic rats. Investigators have also reported the protective effect of $T$. portulacastrum in adriamycin-induced nephrotic syndrome (Karim 2012). Qadir et al. (2018) reported the potential role of medicinal plants as antiatherosclerotic agents. Gong et al. (2018) reported that GPR124 increases the pathogenesis of atherosclerosis via activation of inflammation. In the present study, treatment of diabetic rats with a $T$. portulacastrum extract significantly reduced the expression of GPR124, which confirmed the protective role of this extract against atherosclerosis. Taken together, the results showed that an

Table 4 Protective effect of $T$. portulacastrum extract on lipid profile in streptozotocin induced diabetic rats

\begin{tabular}{lrrrrr}
\hline Parameter & \multicolumn{1}{c}{ Group I } & Group II & \multicolumn{1}{c}{ Group III } & \multicolumn{1}{c}{ Group IV } & Group V \\
\hline sVCAM-1 $(\mathrm{ng} / \mathrm{mL})$ & $542.3 \pm 11.4$ & $1356.4 \pm 16.2^{* * *}$ & $1104.4 \pm 13.2^{\#}$ & $712.3 \pm 10.5^{\# \#}$ & $643.3 \pm 11^{\# \# \#}$ \\
Fibrinogen $(\mathrm{ng} / \mathrm{mL})$ & $2.05 \pm 0.11$ & $3.1 \pm 0.15^{* *}$ & $2.8 \pm 0.14$ & $2.5 \pm 0.13^{\#}$ & $2.4 \pm 0.12^{\# \#}$ \\
\hline
\end{tabular}

${ }^{* *} P<0.01,{ }^{* * *} P<0.001,{ }^{\#} P<0.05,{ }^{\# *} P<0.01$ and ${ }^{\# \#} P<0.001$ 


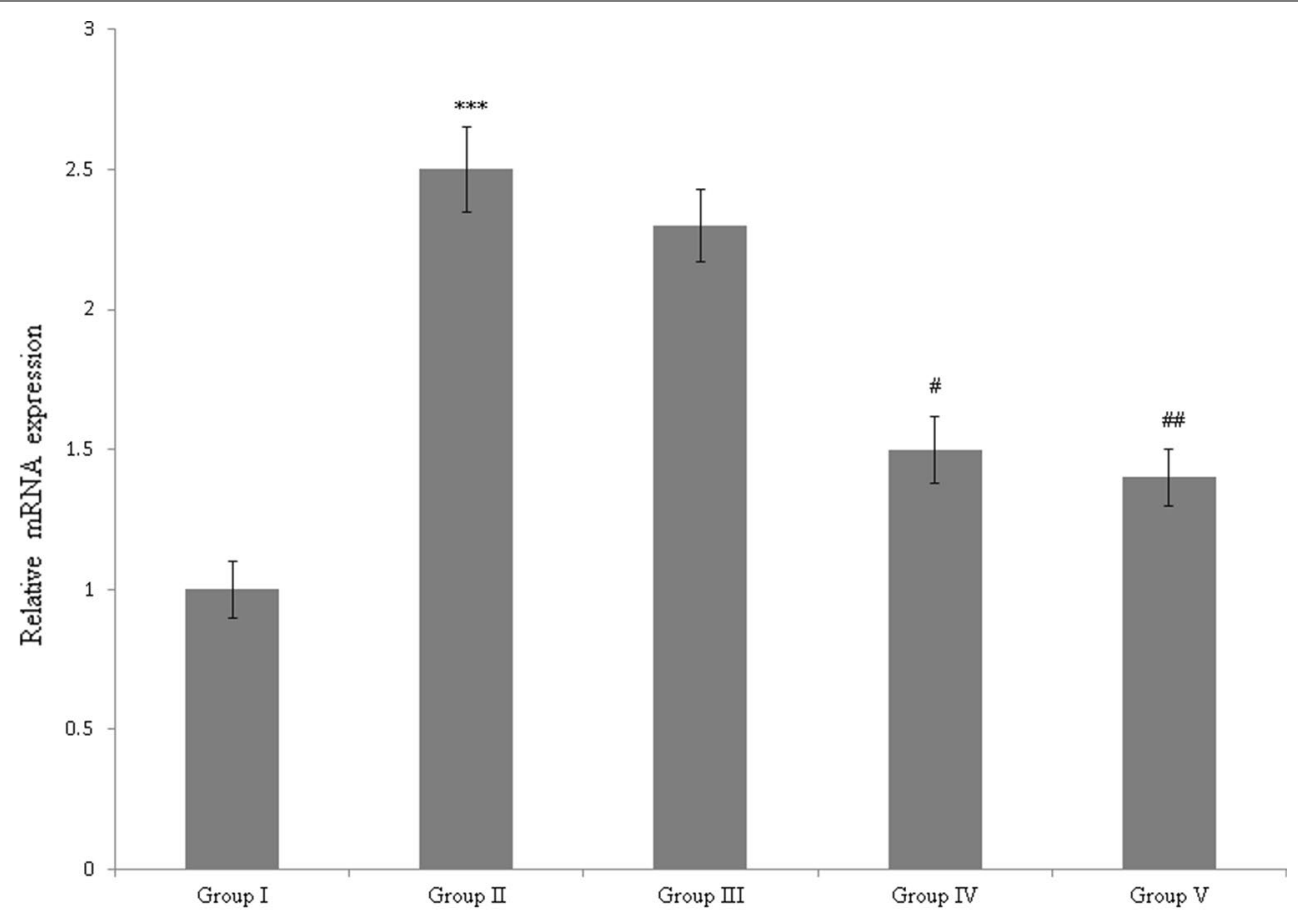

$*: * * P<0.001, \# \mathrm{P}<0.05 \& \# \mathrm{P}<0.01$

Fig. 4 The protective effect of a T. portulacastrum extract on mRNA expression of GPR124 in normal diabetic rats. ${ }^{* * *} P<0.001$ vs. sham; ${ }^{\#} P<0.05$ and ${ }^{\#} P<0.01$ vs. control. $N=6$
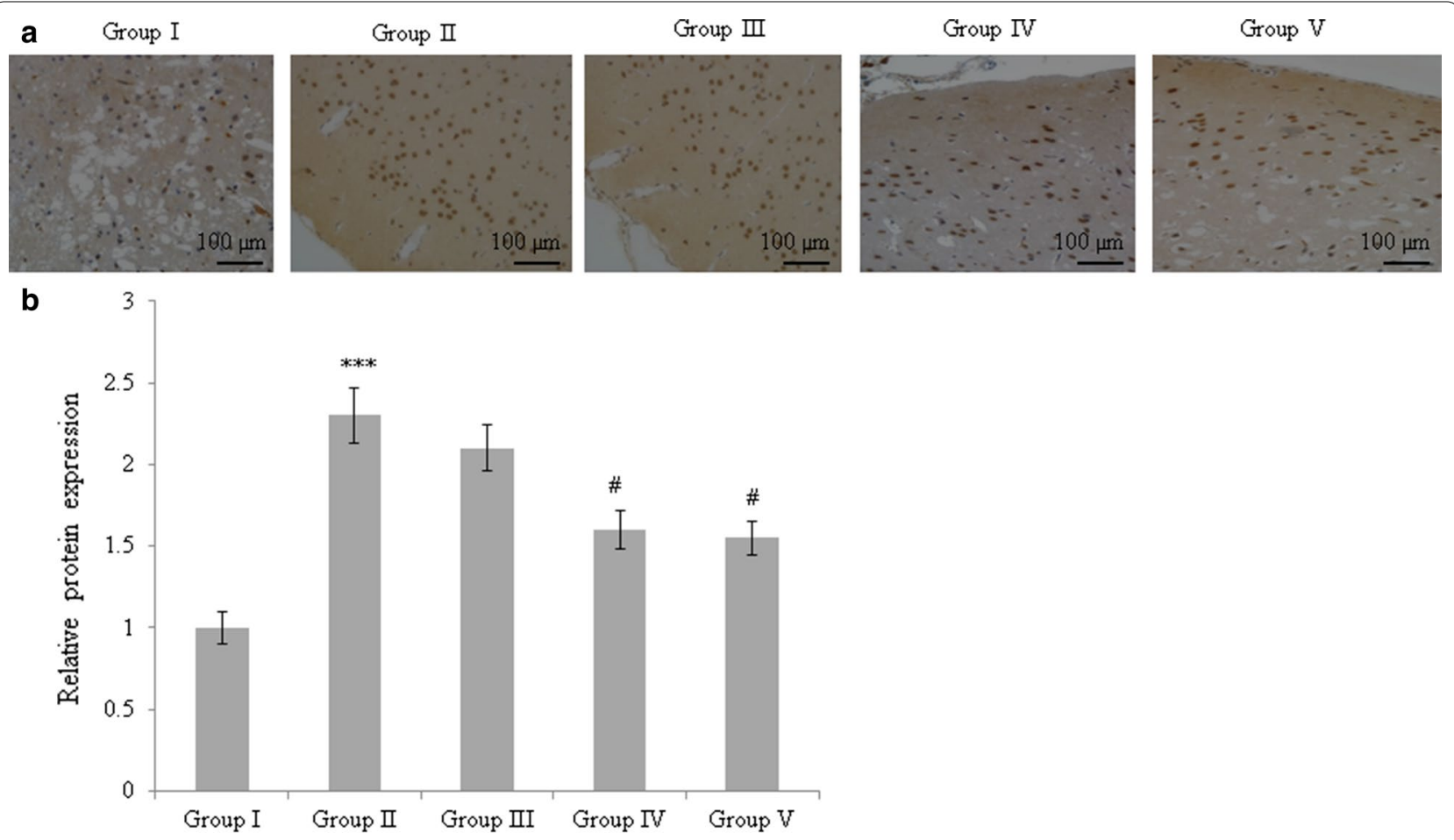

$* * * * p<0.001 \& \# p<0.05$

Fig. 5 The protective effect of a T. portulacastrum extract on protein expression of GPR124 in normal diabetic rats. a Immunohistochemical expression of GPR124 and $\mathbf{b}$ protein expression of GPR124. ${ }^{* * *} P<0.001$ vs. sham; ${ }^{*} P<0.05$ vs. control. $\mathrm{N}=6$. Scale bar is $100 \mu \mathrm{m}$ 
extract of T. portulacastrum was effective against atherosclerosis in streptozotocin-induced diabetic rats.

\section{Acknowledgements}

None.

\section{Authors' contributions}

HW, TG, YC and JD conducted experiments and collected data. FC, JQ and CW carried out data interpretation, review of literature and manuscript drafting. All authors read and approved the final manuscript.

\section{Funding}

None.

\section{Availability of data and materials}

Corresponding author could provide the all experimental data on valid request.

\section{Ethics approval and consent to participate}

All the animal experiments were approved by ethics committee of The Second Affiliated Hospital of Xi'an Jiaotong University, Xi'an, Shaanxi, China.

\section{Consent for publication}

Not applicable.

\section{Competing interests}

The authors declare that they have no competing interests.

\section{Author details}

${ }^{1}$ Department of Cardiology, The Second Affiliated Hospital, Xi'an Jiaotong University, Xi'an 710004, Shaanxi, China. ${ }^{2}$ Department of Cardiology, Shaanxi Provincial People's Hospital, Xi'an 710068, Shaanxi, China. ${ }^{3}$ Department of Gastroenterology, The Affiliated Children Hospital, Xi'an Jiaotong University, Xi'an 710003, Shaanxi, China. ${ }^{4}$ Department of Functional Examination, Shaanxi Provincial People's Hospital, Xi'an 710068, Shaanxi, China.

Received: 22 August 2019 Accepted: 17 October 2019

Published online: 31 October 2019

\section{References}

Aberare OL, Okuonghae P, Mukoro N, Dirisu JO, Osazuwa F, Odigie E, Omoregie R (2011) Triglycerides, total cholesterol, high density lipoprotein cholesterol and low density lipoprotein cholesterol in rats exposed to premium motor spirit fumes. N Am J Med Sci 3(6):277-280

Aikawa M, Rabkin E, Sugiyama S (2001) An HMG-CoA reductase inhibitor cerivastatin, suppresses growth of macrophages expressing matrix metalloproteinases and tissue factor in vivo and in vitro. Circulation 103(2):276-283

Anil TP, Gayatri DG, Bhanudas SK (2018) Antidepressant effect of Hedyotis corymbosa extracts in olfactory bulbectomy rats. Pharmacogn Res 10:213-217

Anreddy RNR, Porika M, Yellu NR, Devarakonda RK (2010) Hypoglycemic and hypolipidemic activities of Trianthema portulacastrum Linn. plant in normal and alloxan induced diabetic rats. Int J Pharmacol 6:129-133

Bader M (2010) Rat models of cardiovascular diseases. Methods Mol Biol 597:403-414

Balic M, Rapp N, Stanzer S, Lin H, Strutz J, Szkandera J, Daidone MG, Samonigg H, Cote RJ, Dandachi N (2011) Novel immunofluorescence protocol for multimarker assessment of putative disseminating breast cancer stem cells. Appl Immunohistochem Mol Morphol 19(1):33-40
Bryan NS, Grisham MB (2007) Methods to detect nitric oxide and its metabolites in biological samples. Free Radic Biol Med 43(5):645-657

Cho DS, Woo S, Kim S, Byrne CD, Kong JH, Sung KC (2012) Estimation of plasma apolipoprotein $B$ concentration using routinely measured lipid biochemical tests in apparently healthy Asian adults. Cardiovasc Diabetol 18(11):55

Ference BA, Ginsberg HN, Graham I (2017) Low-density lipoproteins cause atherosclerotic cardiovascular disease. 1. Evidence from genetic, epidemiologic, and clinical studies. A consensus statement from the European Atherosclerosis Society Consensus Panel. Eur Heart J 38(32):2459-2472

Gimbrone MA Jr, Garcia-Cardena G (2016) Endothelial cell dysfunction and the pathobiology of atherosclerosis. Circ Res 118(4):620-636

Gong DM, Zhang YL, Chen DY, Hong LJ, Han F, Liu QB, Jiang JJ, Lu YM (2018) Endothelial GPR124 exaggerates the pathogenesis of atherosclerosis by activating inflammation. Cell Physiol Biochem 45(2):547-557

Graham ML, Janecek JL, Kittredge JA, Hering BJ, Schuurman HJ (2011) The streptozotocin-induced diabetic nude mouse model: differences between animals from different sources. Comp Med 61(4):356-360

Itabe H (2012) Oxidized low-density lipoprotein as a biomarker of in vivo oxidative stress: from atherosclerosis to periodontitis. J Clin Biochem Nutr 51(1):1-8

Jaipersad AS, Lip GY, Silverman S (2014) The role of monocytes in angiogenesis and atherosclerosis. J Am Coll Cardiol 63(1):1-11

Karim S (2012) Effects of Biskhapra (Trianthema portulacastrum Linn.) leaves extract in adriamycin induced nephrotic syndrome. Int J Green Pharm 5:329-335

Kumar A, Saluja AK, Shah UD, Mayavanshi AV (2007) Pharmacological potential of Albizzia lebbneck: a review. Pharmacogn Rev 1:171-174

Masatoshi M, Nobuo O, Shinichi S, Shahabuddin A, Jen-Yue T, Peter FK, Sana $S$ (2001) The role of aldose reductase in sugar cataract formation: aldose reductase plays a key role in lens epithelial cell death (apoptosis). Chem Biol Interact 130-132:617-625

Matsumoto S, Gotoh N, Hishinuma S (2014) The role of hypertriglyceridemia in the development of atherosclerosis and endothelial dysfunction. Nutrients 6(3):1236-1250

Qadir M, Manzoor A, Akash MSH (2018) Potential role of medicinal plants for anti-atherosclerosis activity. Bangladesh J Pharmacol 13:59

Sharma SB, Tanwar RS, Rini AC, Singh UR, Gupta S, Shukla SK (2010) Protective effect of Morus rubra L. leaf extract on diet-induced atherosclerosis in diabetic rats. Indian J Biochem Biophys 47(1):26-31

Shyam sunder A, Rama A, Narsimha R, Rajeshwar Y, Gangarapu K, Prasad D, Baburao B, Thirumurugu S, Karthik A (2010) Protective effect of methanolic extract of Trianthema portulacastrum in atherosclerotic diet induced renal and hepatic changes in rats. Der Pharmacia Lettre 2(1):540-545

Sofowora A, Ogunbodede E, Onayade A (2013) The role and place of medicinal plants in the strategies for disease prevention. Afr J Tradit Complement Altern Med 10(5):210-229

Wang Z, Yang Y, Xiang X, Zhu Y, Men J, He M (2010) Estimation of the normal range of blood glucose in rats. J Hyg Res 39(2):133-137

Ye P, Cheah IK, Halliwell B (2013) High fat diets and pathology in the guinea pig atherosclerosis or liver damage? Biochim Biophys Acta 1832:355-364

Zhang J, Liang R, Wang L (2013) Effects of an aqueous extract of Crataegus pinnatifida Bge var major NEBr fruit on experimental atherosclerosis in rats. J Ethnopharmacol 148(2):563-569

\section{Publisher's Note}

Springer Nature remains neutral with regard to jurisdictional claims in published maps and institutional affiliations. 